\title{
Clusters of infectious diseases in German nursing homes - observations from a prospective infection surveillance study, October 2008 to August 2009
}

M Schulz (math.schulz@googlemail.com) ${ }^{1}$, M Mielke $^{1}$, N Wischnewski $^{1}$

1. Division Applied Infection Control and Hospital Hygiene, Department of Infectious Diseases, Robert Koch Institute, Berlin, Germany

Citation style for this article:

Schulz M, Mielke M, Wischnewski N. Clusters of infectious diseases in German nursing homes - observations from a prospective infection surveillance study, October 2008 to August 2009.

Euro Surveill. 2011;16(22):pii=19881. Available online: http://www.eurosurveillance.org/ViewArticle.aspx?Articleld=19881

A prospective infection surveillance study was carried out among residents of seven nursing homes in and around Berlin, Germany, from October 2008 to August 2009. A considerable number of infections were found to occur in clusters. Active surveillance was carried out using pre-established case definitions of infections in nursing homes (McGeer criteria). Case finding was based on routine nursing files. Infection rates were calculated per 1,000 resident days. Clusters were identified using a pre-established definition. In total 511 residents were observed during 74,626 resident days (rd), and 393 infections occurred in 243 participants, giving an overall incidence of infection of 5.3 per $1,000 \mathrm{rd}$. The most common infections were gastrointestinal infections ( $n=122 ; 1.6 / 1,000 \mathrm{rd})$, acute respiratory disease $(n=86 ; 1.2 / 1,000 \mathrm{rd})$ and urinary tract infections $(n=71$; 1.0/1,000 rd). Seven clusters involving 74 infections in 57 residents were observed: three of acute respiratory disease, three of acute gastrointestinal disease and one of conjunctivitis. Attack rates varied between $11 \%$ and $61 \%$. Clusters occurred frequently in the observed nursing homes and could be detected by infection surveillance based on routine documentation.

\section{Background}

Clusters of infectious diseases can have major impact on healthcare facilities resulting in increased morbidity and mortality [1]. Nursing homes pose unique challenges in early cluster identification and control as elderly people often present with atypical signs of disease. They are also likely to develop a more severe course of disease, often requiring hospitalisation [2-4]. Delivery of care can be compromised by associated illness and absenteeism among staff [5]. We focus here on clusters of acute respiratory disease (ARD) and gastrointestinal disease (GID) as these seem to predominate in this setting [1].

Up to $60 \%$ of residents can be affected during outbreaks in nursing homes $[6,7]$, many of whom develop complications or suffer functional decline [8]. Case fatality rates as high as $30-55 \%$ have been observed in clusters of ARD $[7,9,10]$.
A wide range of viruses have been identified as aetiological agents of ARD in nursing homes [11], including influenza viruses, respiratory syncytial virus, rhinovirus and human metapneumovirus. The spectrum of bacteria causing outbreaks of pneumonia in nursing homes includes Bordatella pertussis, Streptococcus pneumoniae and Legionella pneumophila. Multiple routes of transmission have been identified in bacterial outbreaks such as staff-to-resident transmission and transmission via contaminated environment. Viral outbreaks preceding outbreaks of bacterial pneumonia have been described [12], leading to prolonged illness.

Another common problem among residents of longterm care facilities is GID [13]. The aetiology of diarrhoea and/or vomiting in the elderly may be noninfectious, a fact that can complicate the detection of communicable GID in nursing homes [13]. In infectious GID, viruses frequently are the causative agents, most notably norovirus, but also bacterial outbreaks of gastrointestinal disease have been reported [14-16]. Clostridium difficile seems to play an increasing role in diarrhoeal disease in nursing homes and outbreaks have been reported [17]. Other infectious diseases that have caused outbreaks in long-term care facilities include conjunctivitis, scabies and skin infections [1].

Prospective surveillance for infections was carried out among residents of seven nursing homes in and around Berlin. As a considerable number of infections turned out to occur in clusters, these clusters are described here in more detail, and we estimate their impact on total infection rates.

\section{Methods}

In each of seven nursing homes in Germany, a prospective infection surveillance study was carried out over a period of six months between October 2008 and August 2009. The nursing homes were situated in or near Berlin. The project was introduced during lectures for nursing home personnel responsible for hygienic matters. Interested institutions were included if 
they fulfilled the following criteria: institutions with a majority of elderly ( 755 years) permanent residents, for whom constant supervision and nursing care are provided. Specialised facilities (e.g. facilities for mentally handicapped residents or for patients needing assisted ventilation) were excluded. The study included only residents who were in a stable medical condition, did not need constant specialised care (e.g. assisted ventilation) and showed no signs of infection at the start of the observation period. Residents newly admitted to the nursing home during the observation period were also asked to participate (open cohort study).

\section{Data collection and case finding}

At the beginning of the study, we collected for all participants demographic data, diagnosis of chronic diseases, score on the Braden scale (a multidimensional scoring system assessing a person's functional status in order to estimate the risk of developing pressure ulcers) and information on currently used medical devices such as urinary catheters.

Infections were identified either by the attending physician or by abstracting data from nursing files using previously described definitions for infection surveillance in long-term care patients (McGeer criteria) [18]. Residents' charts were reviewed for signs and symptoms of infection every second week by two external doctors. Antibiotic treatment and microbiological results that had been ordered by the attending physician were documented to further characterise infections. The study was observational only and no attempt was made to influence the routine documentation of physicians or nurses.

\section{Cluster analysis}

A cluster was defined as infections of the same type according to the applied criteria for infection (McGeer criteria) affecting at least $10 \%$ of the study population within a time span of 21 days. As the case definitions of influenza-like illness, bronchitis and pneumonia are similar these diagnoses were combined as ARD.

One cluster of respiratory infections was characterised by a high attack rate and case fatality rate. In a retrospective cohort study of that cluster, additional data for all residents living in the affected nursing home were collected using routine documentation.

Cases in this cluster were defined as all residents fulfilling, between 15 December 2008 and 15 February 2009, the following case definition: two or more of the following symptoms: body temperature higher than $37.5^{\circ} \mathrm{C}$, acute cough, acute shortness of breath, deteriorating mental or functional status. Absenteeism among staff was estimated using sick-reports.

\section{Ethical considerations}

The regional committee for medical research ethics consented to the study. The study did not entail any direct contact with patients. Residents or their legal guardians had to give informed consent in order to participate.

\section{Statistical analyses}

All data were analysed using the statistical programmes Epi Info version 3.5.1 and OpenEpi. Incidences of infection were calculated as the number of infections per 1,000 resident days $(\mathrm{rd})$, (days that a resident is actually present in the home and not infected). The 95\% confidence interval $(\mathrm{Cl})$ for infection rates was calculated using Mid-P exact test with Miettinen's modification as described elsewhere [19]. The odds ratio was calculated as described by Martin et al. [20].

\section{Results}

Seven nursing homes participated in this prospective cohort study, all situated in or near Berlin. In total 408 residents entered the study on day 1 . Another 102 residents were enrolled at various points later during the

\section{TABLE 1}

Characteristics of facilities and patient cohorts, infection incidence study, Germany, October 2008-August 2009

\begin{tabular}{|c|c|c|c|c|c|c|c|c|}
\hline Nursing home & A & B & C & D & $\mathrm{E}$ & $\mathrm{F}$ & G & Total \\
\hline Period of observation & $\begin{array}{l}\text { Oct o8- } \\
\text { Mar og }\end{array}$ & $\begin{array}{c}\text { Dec o8- } \\
\text { May o9 }\end{array}$ & $\begin{array}{c}\text { Dec o8- } \\
\text { May o9 }\end{array}$ & $\begin{array}{c}\text { Mar 09- } \\
\text { Aug og }\end{array}$ & $\begin{array}{c}\text { Mar 09- } \\
\text { Aug og }\end{array}$ & $\begin{array}{c}\text { Feb o9- } \\
\text { Jul o9 }\end{array}$ & $\begin{array}{c}\text { Mar 09- } \\
\text { Aug og }\end{array}$ & $\begin{array}{l}\text { Oct o8- } \\
\text { Aug og }\end{array}$ \\
\hline Number of beds & 40 & 28 & 115 & 108 & 56 & 115 & 196 & 658 \\
\hline Number of wards & 1 & 1 & 3 & 5 & 2 & 3 & 7 & 22 \\
\hline Residents day 1 & 38 & 28 & 105 & 104 & 54 & 113 & 130 & 572 \\
\hline Bed occupancy rate day 1 (\%) & 95 & 100 & 91 & 96 & 96 & 98 & 66 & 87 \\
\hline Participants day 1 & 38 & 28 & 68 & 61 & 36 & 47 & 130 & 408 \\
\hline Participation rate day 1 (\%) & 100 & 100 & 65 & 59 & 67 & 42 & 100 & 71 \\
\hline Total number of participants & 44 & 36 & 72 & 63 & 36 & 49 & 211 & 511 \\
\hline Resident days $^{\mathrm{a}}$ & 6,951 & 4,691 & 10,853 & 10,483 & 6,541 & 8,151 & 26,956 & 74,626 \\
\hline Deaths during study & 6 & 9 & 15 & 7 & 1 & 4 & 37 & 79 \\
\hline Termination of study due to other reasons & 1 & 0 & 1 & 1 & 0 & 1 & 6 & 9 \\
\hline
\end{tabular}

${ }^{\text {a }}$ Days on which a resident is present in the nursing home and not infected. 
study. Seventy-nine of the 506 participating residents died during the study and nine moved away from their nursing home. Data about the facilities are presented in Table 1. In one nursing home (G) medical care was provided by one physician based in the facility. In the remaining nursing homes medical care was provided by various community-based general practitioners.

From October 2008 to August 2009, 511 residents with $74,626 \mathrm{rd}$ were observed. The mean age of residents was 85 years (median 86 years, range 31-104 years), and $410(80 \%)$ were female. The median length of stay of residents in their respective nursing home was 1.6 years. Some 134 residents (26\%) had diabetes mellitus and $62(12 \%)$ of them were insulin-dependant. Thirtyeight patients (7\%) suffered from chronic obstructive pulmonary disease. Twenty-eight ( $5 \%$ ) had pressure sores and 12 (2\%) leg ulcers. Thirty-six (7\%) had a urinary catheter and 20 (4\%) an enteral feeding tube. Some $314(61 \%)$ of the residents were to some degree disoriented in time or space. In total 282 (55\%) could walk independently, 187 (37\%) were dependant on a wheelchair and 40 (8\%) were bedridden.

\section{Overall infection rate}

A total of 393 infections occurred in 243 participants. The overall incidence of infection was 5.3 per $1,000 \mathrm{rd}$ (95\% Cl: 4.77-5.81). Nursing home-specific incidence rates varied considerably (range: $3 \cdot 0-13.4 / 1,000 \mathrm{rd}$ ). The most common infections were gastrointestinal $(\mathrm{n}=122 ; 1.6 / 1,000 \mathrm{rd} ; 95 \% \mathrm{Cl}: 1.36-1.94)$, acute respiratory disease $(n=86 ; 1.2 / 1,000 \mathrm{rd} ; 95 \% \mathrm{Cl}: 0.93-1.42)$, urinary tract $\left(n=71 ; 1.0 / 1,000 \mathrm{rd} ; 95 \% \mathrm{Cl}: 0.75^{-1.19}\right)$, viral and bacterial conjunctivitis $(n=35 ; 0.5 / 1,000 \mathrm{rd}$; $95 \% \mathrm{Cl}: 0.32-0.65)$, common cold $(n=27 ; 0.4 / 1,000 \mathrm{rd}$; 95\% Cl: $0.24-0.52)$ and soft tissue infection $(n=24$; $0.3 / 1,000 \mathrm{rd}$; $95 \% \mathrm{Cl} 0.21-0.47)$.

\section{Clusters of infection}

Seven clusters could be identified in four of the seven observed nursing homes (Table 2), three ARD clusters, three GID clusters and one of infectious conjunctivitis.
Clusters of other diseases such as skin infections or urinary tract infections could not be identified.

Six clusters occurred in winter months, five of them in January. Attack rates based on case finding using McGeer criteria varied between $11 \%$ and $60 \%$ (Table 2). The contribution of infections occurring in clusters to the overall infection incidence rate was $19 \%$. Some 31 ARD infections (36\%), 38 GID infections (31\%) and five conjunctivitis infections (14\%) occurred in clusters. We systematically recorded the microbiological probes ordered by the attending physicians and to our knowledge, only one cluster (G-GID) was investigated further with microbiological methods. Thirteen GID cases occurred in one ward in nursing home $\mathrm{G}$ between 2 and 5 May, and norovirus was identified in the stool of three symptomatic residents.

One cluster of ARD (B-ARD) showed high attack and case fatality rates. The population of the affected nursing home (B) consisted of 29 very old women (mean age 91 years). They were moderately impaired according to the Braden scale ( $n=21$ at low risk), with few underlying diseases. Only one resident had a medical device (urinary catheter). Fifteen nurses and three community-based general practitioners provided medical care to the residents. All resident rooms were single rooms with shower and toilet.

The first case of respiratory infection among the residents of nursing home B occurred on 11 January 2009. In total, 19 of 29 residents fulfilled the case definition, all within seven days after onset of disease in the index case. The epidemiological curve shows a sharp rise of new infections on two subsequent days. Six of the affected residents died, all within 10 days after presentation of first signs of illness. Seven residents had to be hospitalised and another eight received systemic antibiotic treatment as prescribed by their general practitioner. The cluster stopped within seven days without specific control measures. To our knowledge no attempt was made to isolate an aetiological agent.

\section{TABLE 2}

Time span, type of infection and attack rates for clusters of infections, nursing homes, Germany, October 2008-August 2009

\begin{tabular}{|c|c|c|c|c|c|c|}
\hline Nursing home & Disease & First case(date) & Last case (date) & $\begin{array}{c}\text { Number of } \\
\text { cases }\end{array}$ & $\begin{array}{c}\text { Number of } \\
\text { exposed }\end{array}$ & Attack rate \\
\hline A & Acute respiratory disease (A-ARD) & $18 \operatorname{Jan} 2009$ & $26 \operatorname{Jan} 2009$ & 6 & 38 & $16 \%$ \\
\hline A & Gastrointestinal disease (A-GID) & 21 Jan 2009 & 31 Jan 2009 & 9 & 38 & $24 \%$ \\
\hline B & Acute respiratory disease (B-ARD) ${ }^{a}$ & $15 \operatorname{Jan} 2009$ & $24 \operatorname{Jan} 2009$ & 13 & 28 & $46 \%$ \\
\hline B & Gastrointestinal disease (B-GID) $^{\mathrm{a}}$ & 17 Jan 2009 & 8 Feb 2009 & 17 & 28 & $61 \%$ \\
\hline B & Conjunctivitis (B-Con) & 9 Jan 2009 & 10 Jan 2009 & 5 & 28 & $18 \%$ \\
\hline $\mathrm{C}$ & Acute respiratory disease (C-ARD) & 10 Jan 2009 & $26 \operatorname{Jan} 2009$ & 12 & 72 & $17 \%$ \\
\hline G & Gastrointestinal disease (G-GID) & 2 May2009 & 3 May 2009 & 12 & 29 & $41 \%$ \\
\hline
\end{tabular}

${ }^{a}$ Clusters which were further analysed 
Seventeen of the 29 residents had received seasonal influenza immunisation in the autumn of 2008. There was no significant difference in the number of cases or case fatality rate between the vaccinated and the unvaccinated group. No significant risk factor could be identified for development of disease. A lower score on the Braden scale (i.e. greater functional disability) and incontinence were factors significantly associated with fatal outcome (Tablez).

Concomitantly with this respiratory cluster, a cluster of gastrointestinal disease occurred in nursing home $B$, which affected both staff and residents. Overall, 17 residents were sick and presented primarily with vomiting and diarrhoea. Five of the residents affected by GID also suffered from ARD. In addition, seven of 15 staff members reported sick with ARD or GID during the cluster. The first three cases of ARD among staff members occurred before the first case among residents. No fatal cases occurred among staff members.

\section{Discussion}

Although clusters of infections in nursing homes have been widely described, the systematic recognition of increased rates of certain diseases is hampered by the lack of established infection surveillance systems. Furthermore, systematic laboratory investigations of infections or clusters of infection in the context of prospective infection surveillance studies are rare in this setting. When surveilling the population of seven nursing homes for the development of infections we identified seven clusters of infections including one with high attack rate and mortality. The spectrum of clusters included acute respiratory disease, gastrointestinal disease and conjunctivitis. This is in accordance with the patterns described in the published literature $[1,2,7,11,13,14]$.

Only one cluster of gastrointestinal disease was investigated microbiologically and norovirus was detected in the stool of three symptomatic residents. In this nursing home $(G)$, medical care was provided by a

\section{TABLE 3}

Univariate analysis of risk factors for development of acute respiratory disease and fatal outcome, nursing home B, Germany, 11-19 January $2009(\mathrm{n}=19)$

\begin{tabular}{|l|c|c|}
\hline & Disease OR $(95 \% \mathrm{Cl})$ & $\begin{array}{c}\text { Fatal outcome OR } \\
(95 \% \mathrm{Cl})\end{array}$ \\
\hline Age $\geq 90$ years & $2.1(0.4-11.0)$ & $3.0(0.3-88.3)$ \\
\hline Disorientated & $2.0(0.4-10.7)$ & $5.3(0.5-157)$ \\
\hline Incontinence & $1.4(0.2,12.6)$ & $18.5(1.6-633.6)$ \\
\hline High level of care & $0.7(0.1,3.9)$ & $4.0(0.4-117.7)$ \\
\hline Not able to walk & $2.3(0.2,65.6)$ & $2.6(0.2-32.5)$ \\
\hline Low Braden Score & $1.4(0.2-12.6)$ & $18.5(1.6-633.6)$ \\
\hline $\begin{array}{l}\text { Influenza vaccina- } \\
\text { tion }\end{array}$ & $0.7(0.1-3.7)$ & $2.2(0.3-22.8)$ \\
\hline
\end{tabular}

$\mathrm{Cl}$ : confidence interval; OR: odds ratio. nursing home-based physician, for whom it may be easier to recognise higher rates of infection among the residents.

Due to the high number of affected residents as well as the severity of the disease, one outbreak of ARD was investigated in more detail. Although no aetiological agent was identified, we assume that viral pulmonary disease was the most probable cause of the cluster, based on the rapid spread of disease, the high case fatality rate and the fact that both residents and staff members were affected. It can be assumed that the very high age of the population (mean age 91 years) has contributed to the high mortality rate. As residentto-resident contact was limited within the institution, staff-to-resident transmission could have been an important mode of transmission [21]. As exact information concerning start and duration of illness among staff members could not be obtained, we were not able to fully investigate this question. The cluster was further complicated by a concurrent cluster of gastrointestinal disease.

\section{Study limitations}

Since any intervention including systematic microbiological analyses was beyond the scope of this study, aetiological diagnosis could only be based upon diagnostic steps taken by the attending physicians. In addition, the evaluation of infection control measures during a cluster was beyond the scope of this study. As documentation was not standardised and the vigilance of nurses was not influenced in an active way infections with minor symptoms may have been underreported, which may explain the relative low incidence of common cold. During clusters staff awareness could be higher, resulting in increased reporting and documentation of symptoms. Thus the contribution of clustered infections to overall infection rates could have been overestimated. Furthermore, inter-facility comparison of infection rates cannot be performed because documentation was not standardised and the periods of observation (seasonality) were different.

\section{Conclusions}

Infection surveillance based on routine nursing files can detect clusters of infections, enabling staff to report them to infection control professionals quickly. However, there is need to educate staff at the point of care in order to fully take advantage of this possibility $[22,23]$. Training should aim at standardising symptom documentation and at the correct evaluation of the documentation by designated staff members. In our experience the weekly surveillance of nursing files takes a few hours and could be performed by a quality assurance representative or a nurse in charge of hygienic matters.

Clinical features of infections are often unspecific and cannot usually be used to identify aetiology [2]. Therefore nursing homes need to have plans in place in the event of a cluster including pre-established access 
to rapid laboratory testing for aetiological agents causing respiratory and gastrointestinal infections as well as structures enabling them to quickly initiate appropriate antimicrobial therapies and infection control measures [24]. Identifying pathogens for gastrointestinal disease is important as some pathogens may require modification of hygienic standards such as improved environmental cleaning in the case of $C$. difficile, the change of antiseptic hand rub in the case of norovirus or specific medical treatment [17]. Furthermore, knowing the aetiological agent will direct the search for the source of an outbreak.

Control measures are most effective if initiated early during the course of an cluster $[5,25]$ and early symptomatic treatment is crucial in the treatment of acute respiratory tract infection and severe gastrointestinal disease. Thus, active surveillance under real-time conditions is most desirable. As clusters in nursing homes can occur throughout the year, continuous vigilance is needed, but it may be of additional benefit to intensify surveillance during the winter months.

\section{References}

1. Strausbaugh LJ, Sukumar SR, Joseph CL. Infectious disease outbreaks in nursing homes: an unappreciated hazard for frail elderly persons. Clin Infect Dis. 2003;36(7):870-6.

2. Loeb M, McGeer A, McArthur M, Peeling RW, Petric M, Simor $A E$. Surveillance for outbreaks of respiratory tract infections in nursing homes. CMAJ. 2000;162(8):1133-7.

3. Mattner F, Sohr D, Heim A, Gastmeier P, Vennema H, Koopmans $M$. Risk groups for clinical complications of norovirus infections: an outbreak investigation. Clin Microbiol Infect. 2006;12(1):69-74.

4. Castle NG, Mor V. Hospitalization of nursing home residents: a review of the literature, 1980-1995. Med Care Res Rev. 1996;53(2):123-48.

5. Friesema IH, Vennema $\mathrm{H}$, Heijne $\mathrm{JC}$, de Jager $\mathrm{CM}$, Morroy $\mathrm{G}$, van den Kerkhof JH, et al. Norovirus outbreaks in nursing homes: the evaluation of infection control measures. Epidemiol Infect. 2009;137(12):1722-33.

6. Patriarca PA, Weber JA, Parker RA, Orenstein WA, Hall WN, Kendal AP, et al. Risk factors for outbreaks of influenza in nursing homes. A case-control study. Am J Epidemiol. 1986;124(1):114-9.

7. Vaux S, Poujol I, Bonmarin I, Levy-Bruhl D, Desenclos JC. Surveillance of lower respiratory tract infections outbreaks in nursing homes in France. Eur J Epidemiol. 2009;24(3):149-55.

8. Barker WH, Borisute $\mathrm{H}, \mathrm{Cox} \mathrm{C}$. A study of the impact of influenza on the functional status of frail older people. Arch Intern Med. 1998;158(6):645-50.

9. Goodman RA, Orenstein WA, Munro TF, Smith SC, Sikes RK. Impact of influenza $A$ in a nursing home. JAMA. 1982;247(10):1451-3.

10. Louie JK, Yagi S, Nelson FA, Kiang D, Glaser CA, Rosenberg J, et al. Rhinovirus outbreak in a long term care facility for elderly persons associated with unusually high mortality. Clin Infect Dis. 2005;41(2):262-5.

11. Falsey AR, Dallal GE, Formica MA, Andolina GG, Hamer DH, Leka LL, et al. Long-term care facilities: a cornucopia of viral pathogens. J Am Geriatr Soc. 2008;56(7):1281-5.

12. Fiore AE, Iverson C, Messmer T, Erdman D, Lett SM, Talkington $\mathrm{DF}$, et al. Outbreak of pneumonia in a long-term care facility: antecedent human parainfluenza virus 1 infection may predispose to bacterial pneumonia. J Am Geriatr Soc. 1998;46(9):1112-7.

13. Bennett RG. Diarrhea among residents of long-term care facilities. Infect Control Hosp Epidemiol. 1993;14(7):397-404.

14. Levine WC, Smart JF, Archer DL, Bean NH, Tauxe RV. Foodborne disease outbreaks in nursing homes, 1975 through 1987. JAMA. 1991;266(15):2105-9.
15. Lopman B, Vennema H, Kohli E, Pothier P, Sanchez A, Negredo $A$, et al. Increase in viral gastroenteritis outbreaks in Europe and epidemic spread of new norovirus variant. Lancet. 2004;363(9410):682-8.

16. Svraka S, Duizer E, Vennema H, de Bruin E, van der Veer B, Dorresteijn B, et al. Etiological role of viruses in outbreaks of acute gastroenteritis in The Netherlands from 1994 through 2005. J Clin Microbiol. 2007;45(5):1389-94.

17. Makris AT, Gelone S. Clostridium difficile in the long-term care setting. J Am Med Dir Assoc. 2007;8(5):290-9.

18. McGeer A, Campbell B, Emori TG, Hierholzer WJ, Jackson MM, Nicolle LE, et al. Definitions of infection for surveillance in long-term care facilities. Am J Infect Control. 1991;19(1):1-7.

19. Rothman KJ, Boice JD. Epidemiologic Analysis with a Programmable Calculator. Washington D.C.:United States Department of Health. 1979.

20. Martin D, Austin H. An efficient program for computing conditional maximum likelihood estimates and exact confidence limits for a common odds ratio. Epidemiology. 1991;2(5):359-62.

21. Monto AS, Hornbuckle K, Ohmit SE. Influenza vaccine effectiveness among elderly nursing home residents: a cohort study. Am J Epidemiol. 2001;154(2):155-60.

22. Beck-Sague C, Jarvis WR, Martone WJ. Outbreak investigations. Infect Control Hosp Epidemiol. 1997;18(2):138-45.

23. Tamblyn SE. Recognizing and controlling respiratory disease outbreaks in long-term care facilities. CMAJ. 1997;157(9):1257-60.

24. Arden NH. Control of influenza in the long-term-care facility: a review of established approaches and newer options. Infect Control Hosp Epidemiol. 2000;21(1):59-64.

25. Monto AS, Rotthoff J, Teich E, Herlocher ML, Truscon R, Yen $\mathrm{HL}$, et al. Detection and control of influenza outbreaks in well-vaccinated nursing home populations. Clin Infect Dis. 2004;39(4):459-64. 